\title{
Traditional healers in East Africa
}

\author{
David M. Ndetei FRCPsych
}

Professor of Psychiatry, University of Nairobi; Founder and Director, Africa Mental Health Foundation (AMHF), email dmndetei@mentalhealthafrica.com

Paper presented at the Royal College of Psychiatrists' annual meeting, 10-13 July 2006, Glasgow, UK

\begin{abstract}
ince time immemorial, people from East Africa, and beyond, depended on traditional healers for treatment of all types of disorders, including those related to mental health. Even today, the use of traditional healers is common, despite the introduction of modern drugs. Alternative medicine is growing fast all over the world.

It is estimated that traditional practitioners manage at least $80 \%$ of the healthcare needs of rural inhabitants in East Africa. Research statistics from Kenya and Uganda suggest that $25-40 \%$ of all people seeking medical care at primary health level have problems purely related to mental health and another $25-40 \%$ have a combination of both mental health problems and physical problems (Ndetei \& Muhanji, 1979). It can therefore be expected that at least half of all patients who go to see traditional healers have mental health problems. Data from general hospitals in Kenya suggest that 30-40\% of patients admitted to those facilities have a mental health problem which is not recognised as such by the medical professionals working there. It is also common knowledge that many patients would use both modern medicines (as offered
\end{abstract} in general hospitals) and traditional healers.

So, whichever way one looks at it, traditional healers have as much share, if not a much bigger share, of all the patients seeking medical help at any particular time. This was recognised in Kenya by Dr Otsyula, who reported in 1973 that patients went to hospital only to look for the cure of their illness, whereas they went to see traditional doctors for both the cure and also to find out the cause of their illness. Further, several studies have suggested that many cultures have names for various mental health disorders, implying that they have long recognised them (Otsyula, 1973).

The types of management prescribed by these traditional healers (often concurrently) fall into several main groups. These include the use of herbal preparations (pharmacotherapy) and several types of psychotherapy.

At this point, it is important to differentiate between traditional medicine and witchcraft, although overlaps can be seen, especially in theories of causation. Traditional healers have theories that recognise genetic, social, psychological and environmental factors in the causation and maintenance of illness. They also embrace spiritual causation, usually ancestral. Witchcraft focuses on evil designs, usually on or by close relatives, associates or competitors, and its prescriptions are usually designed to bring pain and suffering or even death to assumed or alleged enemies, based on jealousy, the need to obtain wealth, fame, popularity and so on. This is usually done through agents known as witches. Witches are generally shunned and are often thrown out of their own communities. Witch-doctors are the people who hunt for and bring to book the witches (Otsyula, 1973).

\section{Pharmacotherapy}

The range of herbs used is broad and such herbs are widely available. They are still under study using modern pharmacological assays. An example of a plant with medicinal properties is Rauwolfia, which is rich in reserpine. This plant is found as an ornamental plant in many parts of Kenya and Tanzania, especially around the Mt Kilimanjaro area, where it also grows in the wild. It is known for the treatment of 'madness', by which is meant psychosis, regardless of the cause or type. There is a story of Chief Adetona from Nigeria who travelled to the UK in 1925 with Rauwolfia extracts to treat a Nigerian who had become psychotic there. This was long before any known psychotropic was available in the West (Prince, 1960).

\section{Psychotherapy}

The practice of psychotherapy and behavioural therapy is so very much advanced in traditional practice in East Africa that these therapies as practised in the West are not a match. This is illustrated by a statement by Rappoport \& Dent (1979) on family therapy in Tanzania. They remarked 'nothing we had seen in a Western clinic could compete with the deep power of this ritual'.

In the early 1980s, the present author had the opportunity to sit in on a clinic of a traditional healer deep in a rural area in Kenya. This healer specialised in the treatment of sexual dysfunctions using herbs and psychotherapy. The herbs must have acted very much like Viagra, for they helped men to achieve and sustain erection. But most impressive was the psychotherapeutic and behavioural approach, involving couple therapy. Without ever having heard of the Masters and Johnson technique, and himself never having travelled far from his home, and also being totally illiterate, this traditional healer prescribed almost to the letter that technique for sexual dysfunction. Asked how he learnt about it, he said he had done so from his father, who had learnt from his own father and so on. There were no textbooks. They learnt simply through pupillage.

Family therapy groups and group therapy are prescribed as a form of psychotherapy by many traditional healers. Of course, they do not call it psychotherapy, but in practice it is psychotherapy as we psychiatrists understand it today. The operational procedures are much the same as those practised in the West. In the process of these types of psychotherapy, individual psychodynamics are explored. Compare this with Freud's and others' psychodynamic procedures at the end of 1800 s and early 1900 s and ask yourself who really invented psychotherapy and when! 


\section{Spiritual therapy}

Spiritual therapy attempts to bring peace and harmony between the living and the spiritual world, especially spirits of the ancestors, which are believed to live on after death and continue to influence events in the living world.

Without going into the merits and demerits of their beliefs about the ancestors, what really matters are the effects of the perceived harmony, which, translated into today's thinking, amounts to stress reduction. The effect of reduced stress, especially in relation to immunological response, is not in any doubt, even by today's science. Although psychiatrists may not accept an explanation that does not make sense in terms of modern science, the explanation is not the issue here: what matters are the perceived effects by those who practise spiritual therapy. George Brown and Tirril Harris from London used the word meaning to explain this phenomenon when they wrote about contextual threat (Brown \& Harris, 1978).

\section{Surgical}

A classic example of a traditional surgical intervention is craniotomy as practised by the Kisii and Turkana peoples of Kenya, for the treatment of psychosis related to diseases thought to be located inside the skull. This is, however, not practised today. What are still very much practised are small cuts on various parts of the body to relieve pain or for the insertion of medicines.

\section{Conclusions}

Traditional healers see and manage most of the mental health problems in East Africa. Our understanding of the pharmacology of the herbs they use is limited, but this is not so with psychotherapy. Indeed, the West has a lot to learn from traditional healers in East Africa.

The challenge is to psychiatrists trained on the Western model. Are they willing to learn from the traditional healers? Are they willing to work with them? They can say no to this only to the detriment of the patients they seek to heal, and more significantly to the detriment of science, which they seek to embrace. An even greater challenge is whether they can work together so that they each benefit from what is good from the other.

\section{References}

Brown, G. W. \& Harris, T. O. (1978) The Social Origins of Depression. A Study of Psychiatric Disorders in Women. Tavistock.

Ndetei, D. M. \& Muhanji, J. (1979) The prevalence and clinical presentation of psychiatric illness in a rural setting in Kenya. British Journal of Psychiatry, 135, 269-272.

Otsyula, W. (1973) Native and Western healing: the dilemma of East African psychiatry. Journal of Nervous and Mental Disease, 156 , 297-299.

Prince, R. (1960) The use of Rauwolfia for the treatment of psychoses by Nigerian traditional doctors. American Journal of Psychiatry, 117, 147-149.

Rappoport, H. \& Dent, P. L. (1979) An analysis of contemporary East Africa folk psychotherapy. British Journal of Medical Psychology, 52, 49-54.

\section{Psychiatry in Austria}

\section{W. Wolfgang Fleischhacker ${ }^{1}$ and Johannes Wancata ${ }^{2}$}

${ }^{1}$ Department of Biological Psychiatry, Medical University Innsbruck, Austria, email wolfgang.fleischhacker@uibk.ac.at ${ }^{2}$ Department of Social Psychiatry, Medical University Vienna, Austria

\begin{abstract}
ustria covers an area of some $84000 \mathrm{~km}^{2}$ and has a population of 8.1 million. According to World Bank criteria, Austria is a high-income country. The overall health budget represents $8 \%$ of gross domestic product (World Health Organization, 2005). The state of Austria is divided into nine federal provinces, which have significant legislative rights, including in healthcare provision.

Life expectancy at birth is 76.2 years for males and 82.3 years for females (in 2005). The proportion of the population under the age of 15 years is $15 \%$ and the proportion above 65 years is $17 \%$. Austria is among the 19 countries worldwide which are projected to have at least $10 \%$ of their population aged 80 years or over by the year 2050. Since some mental disorders, such as dementia, increase with age, the number of psychiatric patients will probably rise dramatically.
\end{abstract}

\section{Mental health policy and services}

The number of psychiatric hospital beds has decreased substantially. In the year 2001 there were 4696 psychiatric beds in total (i.e. 59 per 100000 population), down from nearly 12000 beds in 1974 - a decrease of more than $60 \%$.

The National Hospital Plan includes suggestions for the establishment of psychiatric units in general hospitals. Ten psychiatric units in general hospitals have been established, and several others are planned. Most traditional mental hospitals have been transformed to meet the needs of patients with acut mental illness. In addition, some of them have extended their services to people with physical diseases.

Each of the nine provinces has developed a mental health plan. Although there are regional differences between these, the key points of all plans are: a focus on community 